\section{MATING SLUGS}

Caught in flagranti - no wonder it's been a good year for slugs! These photos show two grey garden slugs (Deroceras reticulatum) engaged in a delicate activity. These slugs are simultaneously hermaphroditic, bearing both male and female organs in the same individual. Here, the two participants are intertwined yin-yang-like (top panel), engaged in courtship. The shiny white organ on each slug is the sarcobelum, a penial structure with which the pair mutually stroke each other during the exploratory phase. In the center and bottom panels, one can also see a secretion being transferred from one sarcobelum to the other. The function of this secretion is not well understood, as the sperm are actually transferred in packets extruded from the penial gland, not the sarcobelum, and are transferred externally; there is no intromission. Courtship in this species can last anywhere from 15 minutes to $\sim 2$ hours, whereas actual copulation (i.e. entwining of the penes and transfer of ejaculates) generally takes only a few seconds, up to 1 minute.

For more on the reproductive behaviour of Deroceras slugs, see the following papers and references therein:

Reise H (2007) A review of mating behavior in slugs of the genus Deroceras (Pulmonata: Agriolimacidae). American Malacological Bulletin 23:137-156.
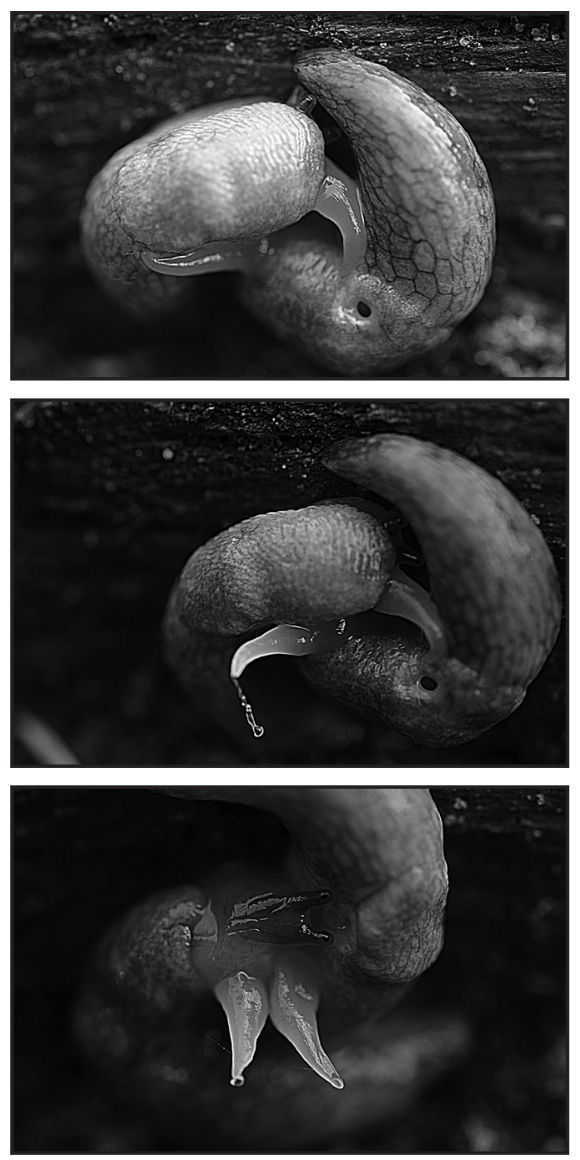

Reise $\mathrm{H}$, Visser S, Hutchinson SMC (2007) Mating behaviour in the terrestrial slug Deroceras gorgonium: is extreme morphology associated with extreme behaviour? Animal Biology 57:197-215.

- Victoria Kjoss, 3426 Clover Place, Regina, SK, S4V 1J1. E-mail:<kjoss@ sasktel.net>

There are always flowers for those who want to see them. 